\title{
BMJ Open Cross-sectional survey: risk-averse French GPs use more rapid-antigen diagnostic tests in tonsillitis in children
}

\author{
Audrey Michel-Lepage, ${ }^{1,2}$ Bruno Ventelou, ${ }^{1,3,4}$ Antoine Nebout, ${ }^{1,5}$ Pierre Verger, ${ }^{1,3}$ \\ Céline Pulcini ${ }^{1,6,7}$
}

To cite: Michel-Lepage A, Ventelou B, Nebout A, et al. Cross-sectional survey: riskaverse French GPs use more rapid-antigen diagnostic tests in tonsillitis in children. $B M J$ Open 2013;3:e003540. doi:10.1136/bmjopen-2013003540

- Prepublication history and additional material for this paper is available online. To view these files please visit the journal online (http://dx.doi.org/10.1136/ bmjopen-2013-003540).

Received 3 July 2013 Revised 3 September 2013 Accepted 24 September 2013

CrossMark

\footnotetext{
${ }^{1}$ Aix Marseille Université (Aix Marseille School of Economics-SESSTIM UMR 912, Inserm IRD), Marseille, France

${ }^{2} \mathrm{HHU}$, Fondation Méditerranée Infection, Marseille, France ${ }^{3}$ ORS PACA, Observatoire Régional de la Santé Provence-Alpes-Côte d'Azur, Marseille, France

${ }^{4}$ CNRS, U6579 (greqam), Marseille, France ${ }^{5}$ INRA, UR 1303 ALISS, F-94200 Ivry-sur-Seine, France ${ }^{6}$ Service d'Infectiologie, $\mathrm{CHU}$ de Nice, Nice, France ${ }^{7}$ Faculté de Médecine, Université Nice-Sophia Antipolis, Nice, France
}

Correspondence to Céline Pulcini; pulcini.c@chu-nice.fr

\section{ABSTRACT}

Objectives: We tested the following hypotheses: (1) risk-averse general practitioners (GPs) might use more Rapid Antigen Diagnostic Tests (RADTs) in tonsillitis in children, probably to decrease their diagnostic uncertainty regarding the aetiology of the disease (viral vs due to group A Streptococcus); and (2) GPs not using RADT might prescribe more antibiotics when they are risk averse.

Design, setting and participants: We conducted a cross-sectional survey of a nationwide French representative sample of 1093 GPs in 2012.

Outcome measures: Multivariate analyses adjusted on the four stratification variables (age, gender, location and volume of activity, ie, the number of annual consultations) were performed to identify the risk domains associated with indicators of good or poor practice.

Results: $69.4 \%$ of GPs were aware of national guidelines regarding tonsillitis and declared that they had taken these guidelines into account for their last paediatric tonsillitis case. $59.1 \%$ declared they used RADT in their last patient aged between 3 and 16 years presenting with tonsillitis; $29.7 \%$ of these tests were positive. Among the GPs who used RADT, $30.7 \%$ prescribed an antibiotic; $98.3 \%$ did either prescribe an antibiotic because of a positive RADT result, or did not prescribe an antibiotic in view of a negative result. Among the GPs who did not use RADT, $50.7 \%$ prescribed an antibiotic. In multivariate analyses, riskaverse GPs declared being more aware of and compliant with guidelines $(O R=1.56, p<0.01)$, and used RADTs more often for their last patient $(O R=1.30, p<0.05)$. Among GPs not using RADT in their last patient, riskaverse GPs prescribed more antibiotics compared with risk-tolerant doctors $(\mathrm{OR}=1.18, \mathrm{p}<0.05)$.

Conclusions: Individual risk attitudes influenced GPs' practices in tonsillitis, particularly the use of RADTs and antibiotic prescriptions.

\section{INTRODUCTION}

Given the current worldwide bacterial resistance crisis, decreasing unnecessary use of antibiotic is crucial. In France, $80 \%$ of all antibiotics administered to humans are

\section{ARTICLE SUMMARY}

Strengths and limitations of this study

- First study to have assessed the impact of individual risk attitudes of physicians on antibiotic prescribing using a standardised measure scale.

- Large nationwide representative sample of general practitioners.

- Based on declarative data, and not on real practices, but standardised questions allowed us to assess the true impact of individual risk attitudes and clinical vignettes have been shown to be a valid tool for measuring the quality of physician practice.

prescribed in the outpatient setting, and general practitioners (GPs) account for $71 \%$ of these prescriptions. ${ }^{1}$

Tonsillitis is one of the leading causes for prescribing antibiotics in the outpatient setting. $^{2}$ Rapid Antigen Diagnostic Tests (RADTs) detecting group A streptococcal infections offer a useful means to reduce unnecessary antibiotic prescriptions: the 2011 French guidelines recommend using these tests in all cases of tonsillitis in children $\geq 3$ years and prescribing antibiotics only in proven group A streptococcal infections ( positive RADT result). ${ }^{3}$ If RADT is not available, the guidelines explicitly state that antibiotic therapy is not required. ${ }^{3}$ However, in France, RADTs are underused for patients presenting with tonsillitis. ${ }^{4}$

Non-compliance with guidelines can be explained by a variety of factors. ${ }^{5}$ At country level, 'uncertainty avoidance' was recently identified in multivariate analysis as one of the national cultural dimensions significantly associated with (inappropriate) use of antibiotics for colds/flu/sore throats, ${ }^{6}$ confirming previous findings. ${ }^{7}$ France is a country with a high uncertainty avoidance score. ${ }^{67}$ At the individual level, recent reviews of qualitative studies identified diagnostic uncertainty as an 
important factor favoring antibiotic misuse. ${ }^{8} 9$ Risk aversion slightly differs from uncertainty avoidance, but, as a close concept largely used in economics, it was interesting to know whether it might play a role in antibiotic prescribing and the use of rapid diagnostic tests in tonsillitis. On the one hand, RADTs decrease diagnostic uncertainty, by establishing that the tonsillitis is bacterial (group A streptococcal infection). One may hypothesise that risk-averse GPs might use RADTs more often, possibly as a way to decrease their diagnostic uncertainty. On the other hand, if GPs are not using RADTs, clinical findings do not allow to reliably differentiate between viral and bacterial tonsillitis. ${ }^{3}$ Thus, one may hypothesise that risk-averse GPs might prescribe more antibiotics when they are not using RADTs since they may be more sensitive to diagnostic uncertainty than risk-tolerant GPs. Consequently, diagnostic uncertainty might lead here to unnecessary antibiotic prescriptions.

In this survey of a nationwide French representative sample of GPs, we wanted to assess the following hypotheses, taking tonsillitis as an example: (1) risk-averse GPs might use more RADTs, probably to decrease their diagnostic uncertainty regarding the aetiology of the disease (viral vs due to group A Streptococcus) and (2) GPs not using RADT might prescribe more antibiotics when they are risk averse.

\section{MATERIAL AND METHODS Sampling}

A panel of French GPs was constituted in June 2010. Its procedures have already been described elsewhere. ${ }^{4}$ Briefly, 5170 GPs were selected by random sampling from the Ministry of Health's exhaustive database of health professionals in France. Sampling was stratified for location of the general practice (urban, peri-urban or rural areas), gender, age $(<49,49-56,>56$ years old $)$ and the number of consultations $(<2849,2849-5494$, $>5494)$ in 2008. Of the 3888 contacted and eligible GPs, $1431(36.8 \%)$ agreed to participate in the panel, that is, to provide regular data on their activity and respond to five consecutive surveys on different topics during a 30-month period. Among the 1136 GPs who participated in the fifth national cross-sectional survey, conducted in November 2012 (attrition rate between the first and fifth cross-sectional surveys: $20.6 \%$ ), the results presented in this study are based on 1093 GPs (43 missing values).

\section{Procedure and questionnaire}

Professional investigators contacted the GPs and interviewed them with computer-assisted telephone interview software, using a standardised questionnaire (see online supplementary file). It collected information about their professional characteristics, their practices regarding tonsillitis and their individual risk attitudes in their daily life, concerning their personal finances and their medical behaviour regarding patients' health, using a
Likert scale from 0 (not at all inclined to take risks) to 10 (totally inclined to take risks). ${ }^{10}{ }^{11}$ We considered a scoring below 5 to be risk averse. ${ }^{10}{ }^{11}$ From the questionnaire we studied the following indicators of compliance with tonsillitis guidelines: awareness and use of national tonsillitis guidelines (indicator 1, reflecting good practice); use of RADT in the last patient aged between 3 and 16 years presenting a tonsillitis (indicator 2 , good

Table 1 Sociodemographic characteristics of the 1093 general practitioners (GPs)

\begin{tabular}{|c|c|}
\hline & Per cent \\
\hline \multicolumn{2}{|c|}{ GPs' characteristics } \\
\hline \multicolumn{2}{|l|}{ Gender } \\
\hline Male & 73.0 \\
\hline Female & 27.0 \\
\hline \multicolumn{2}{|l|}{ Age (years) } \\
\hline$<45$ & 21.2 \\
\hline $45-54$ & 36.3 \\
\hline$>54$ & 42.5 \\
\hline \multicolumn{2}{|c|}{ Medical practice characteristics } \\
\hline \multicolumn{2}{|c|}{ Location of practice } \\
\hline Urban & 21.0 \\
\hline Peri-urban & 18.5 \\
\hline Rural & 60.5 \\
\hline \multicolumn{2}{|c|}{ Volume of activity (number of annual consultations) } \\
\hline$<2849$ & 20.6 \\
\hline $2849-5494$ & 54.3 \\
\hline$>5494$ & 25.1 \\
\hline \multicolumn{2}{|c|}{ Indicators of good practice } \\
\hline \multicolumn{2}{|c|}{ Awareness and use of tonsillitis guidelines } \\
\hline Yes & 69.4 \\
\hline No & 30.6 \\
\hline \multicolumn{2}{|c|}{ Use of RADT in the last patient } \\
\hline Yes & 59.1 \\
\hline No & 40.9 \\
\hline \multicolumn{2}{|c|}{ Good antibiotic prescription practices among GPs using } \\
\hline \multicolumn{2}{|c|}{ RADT } \\
\hline Yes & 98.3 \\
\hline No & 1.7 \\
\hline \multicolumn{2}{|c|}{ Indicator of poor practice } \\
\hline \multicolumn{2}{|c|}{ Antibiotic prescriptions among GPs not using RADT } \\
\hline Yes & 50.7 \\
\hline No & 49.3 \\
\hline \multicolumn{2}{|l|}{ GPs' risk attitudes } \\
\hline \multicolumn{2}{|l|}{ Daily life } \\
\hline Risk-averse & 40.1 \\
\hline Risk-tolerant & 57.2 \\
\hline No answer* & 2.7 \\
\hline \multicolumn{2}{|c|}{ Medical behaviour regarding patients' health } \\
\hline Risk-averse & 64.5 \\
\hline Risk-tolerant & 32.3 \\
\hline No answer & 3.2 \\
\hline \multicolumn{2}{|c|}{ Personal finances } \\
\hline Risk-averse & 56.4 \\
\hline Risk-tolerant & 40.3 \\
\hline No answer & 3.3 \\
\hline
\end{tabular}

*Corresponds to GPs who chose not to answer the question, and to GPs who answered "I do not know ».

RADT, Rapid Antigen Diagnostic Test. 
practice); among GPs who declared using RADT, antibiotic prescription in case of a positive RADT result and absence of antibiotic prescription in case of a negative RADT result (indicator 3, good practice) and among GPs who did not use RADT, prescription of an antibiotic (indicator 4 , reflecting poor practice).

\section{Statistical analysis}

Owing to the panel participants' characteristics, we weighted the data to obtain a representative sample of the national French GP population for age, gender, location and volume of activity. For indicators 1 and 2, multivariate logistic regressions adjusted on the four stratification variables were performed, and for indicators 3 and 4 sample selection models in two steps were used to identify the risk domains associated with indicators of good or poor practice in order to take into account the selection effect of the sample. In the first step, the dependent variable was the use of RADTs; in the second step, the dependent variable was either indicator 3 or 4 . The stratification variables were computed in the first step of the model. All indicators were studied separately in each multivariate analysis. All analyses were performed using SAS V.9.3.

\section{RESULTS}

The sociodemographic characteristics of the participants are presented in table 1. A total of $69.4 \%$ of GPs were aware of national guidelines regarding tonsillitis and declared that they had taken these into account for

Table 2 Association between declared practices regarding tonsillitis and individual risk attitudes, in multivariate analysis $(\mathrm{N}=1093)$

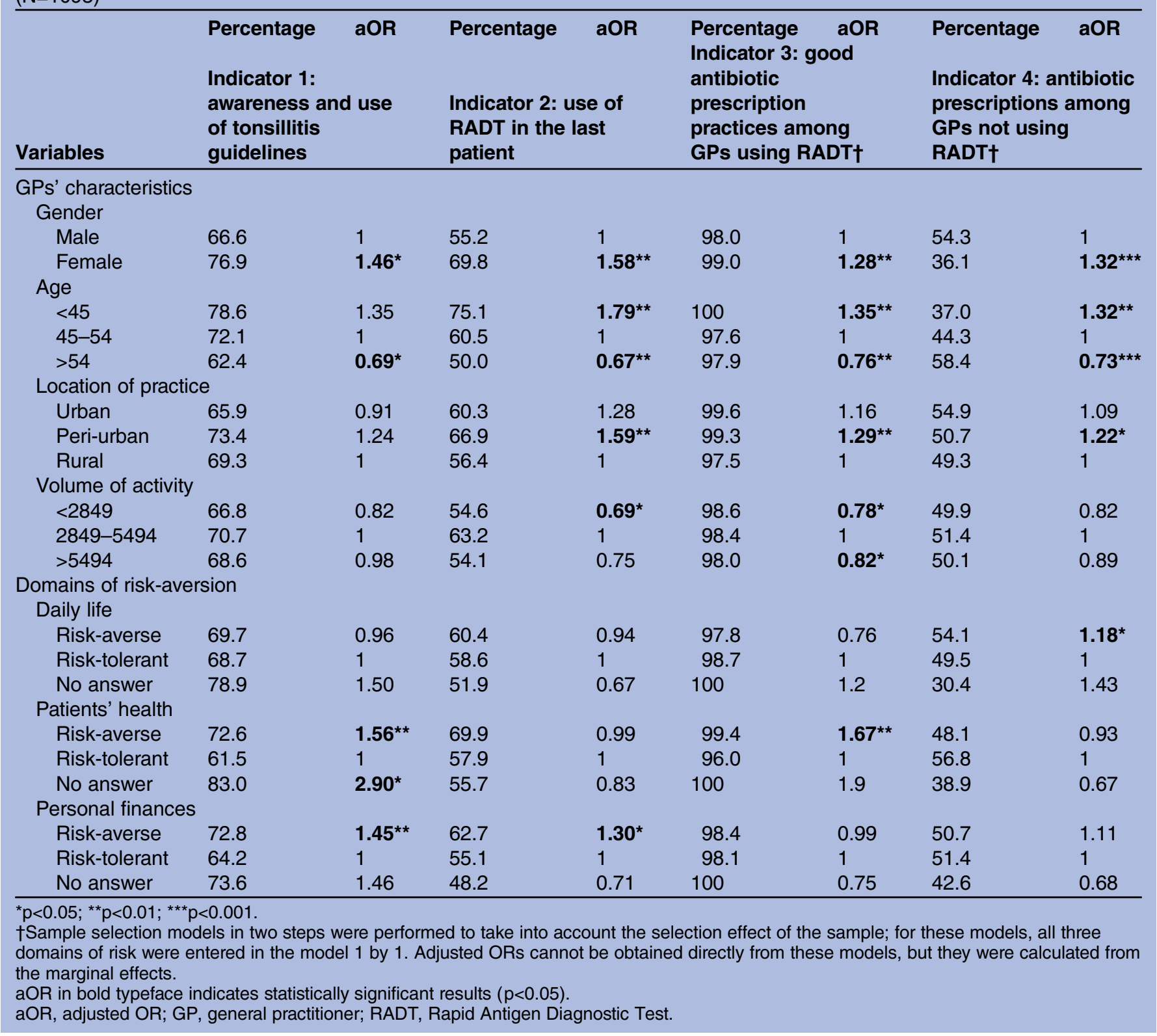


their last tonsillitis case (indicator 1); 59.1\% declared that they used RADT in their last patient aged between 3 and 16 years presenting with tonsillitis (indicator 2); $29.7 \%$ of these tests were positive and antibiotics were prescribed in $30.7 \%$ of the cases when RADT was used. Among the GPs who used RADT, 98.3\% did either prescribe an antibiotic therapy because of a positive RADT result, or did not prescribe an antibiotic therapy in view of a negative result (indicator 3). Among the GPs who did not use RADT, $50.7 \%$ prescribed an antibiotic (indicator 4).

\section{Individual risk attitudes}

The prevalence of risk-averse GPs for the three following domains was as follows: $40.1 \%$ for the daily life scale, $56.4 \%$ for the personal finances one and $64.5 \%$ for the medical behaviour regarding patients' health scale.

\section{Association between practices and individual risk attitudes}

Risk-averse GPs declared being more aware of and compliant with guidelines, and used RADTs more often in their last patient. Among GPs not using RADT in their last patient, risk-averse GPs prescribed more antibiotics compared with risk-tolerant doctors (table 2).

GPs' sociodemographic characteristics also influenced practices: for example, female GPs and GPs $<45$ years old used RADTs more often in their last patient, but prescribed more antibiotics when RADT was not used. GPs with a low volume of activity also used RADTs less often.

\section{DISCUSSION}

Our two hypotheses were verified: we found that risk-averse GPs were using RADTs more often and that a risk-averse behaviour was associated with an increase in antibiotic prescriptions when RADTs were not used. It is possible that the diagnostic uncertainty leading to unnecessary antibiotic prescriptions in tonsillitis leaves room for an increased use of RADTs and, as a consequence, for a decreased use of antibiotics in risk-averse GPs using RADT. RADTs may indeed decrease diagnostic uncertainty, as suggested in the literature..$^{6-9} 12$ RADTs allow the physician to differentiate between viral and bacterial (group A streptococcal infection) tonsillitis, whereas clinical findings do not allow a reliable distinction to be made between viral and bacterial tonsillitis. ${ }^{3}$ These tests are thus a very useful strategy to decrease unnecessary antibiotic prescriptions. Since the financial risk domain was associated with indicators 1 and 2, financial incentives regarding RADT use, included in a pay-for-performance programme, might have an impact on practices.

Our study states original findings, and is the first, to the best of our knowledge, to have assessed the individual risk attitudes of physicians using a standardised measure scale. It is based on declarative data, and not on real practices, and this could be a limitation; however, standardised questions allowed us to assess the true impact of risk attitudes. Furthermore, clinical vignettes have been shown to be a valid tool for measuring the quality of physician practice. ${ }^{13}$ Finally, our results might not be generalisable to other countries, since France is known for its high uncertainty avoidance score, which could be a possible driver behind the observed behaviour. ${ }^{6} 7$

In conclusion, RADTs for tonsillitis can reduce unnecessary antibiotic prescriptions, possibly because they decrease diagnostic uncertainty regarding the aetiology of tonsillitis. Risk aversion has a dual effect: on the one hand, it induces GPs to use more RADTs (and as a consequence to prescribe less antibiotics), whereas on the other it also induces GPs to prescribe more antibiotics when RADTs are not used.

Acknowledgements We would like to thank all GPs who participated to the survey as well as members of the supervisory committee of the French Panel of General Practices.

Contributors $\mathrm{CP}, \mathrm{AN}$ and BV designed the study. CP. wrote the article. AM-L performed the statistical analysis. AM-L, AN, BV and PV reviewed the study protocol and the article.

Funding The French Panel of General Practices received funding from Direction de la Recherche, des Etudes, de l'Evaluation et des Statistiques (DREES) - Ministère du travail, des relations sociales, de la famille, de la solidarité et de la ville, Ministère de la santé et des sports, through a multiannual agreement on objectives. None of the above bodies had any role in study design; the collection, analysis, and interpretation of data; the writing of the article or the decision to submit this article for publication.

Competing interests The work of CP was supported by the 'Méditerranée Infection' foundation (a non-profit-making foundation, http://www. mediterranee-infection.com/), which paid for her accommodation and travel expenses when coming to Marseille. AM-L received a $\mathrm{PhD}$ grant from the same 'Méditerranée Infection' foundation. AN was supported by ‘Aix Marseille School of Economics'.

Ethics approval The National Data Protection Authority (Commission Nationale Informatique et Libertés), responsible for ethical issues and protection of individual data in France, approved the panel and its procedures.

Provenance and peer review Not commissioned; externally peer reviewed.

Data sharing statement No additional data are available.

Open Access This is an Open Access article distributed in accordance with the Creative Commons Attribution Non Commercial (CC BY-NC 3.0) license, which permits others to distribute, remix, adapt, build upon this work noncommercially, and license their derivative works on different terms, provided the original work is properly cited and the use is non-commercial. See: http:// creativecommons.org/licenses/by-nc/3.0/

\section{REFERENCES}

1. Agence Nationale de Sécurité du Médicament et des Produits de Santé. Dix ans d'évolution des consommations d'antibiotiques en France. 2013

2. Chahwakilian $P$, Huttner B, Schlemmer B, et al. Impact of the French campaign to reduce inappropriate ambulatory antibiotic use on the prescription and consultation rates for respiratory tract infections. J Antimicrob Chemother 2011;66:2872-9.

3. Société de Pathologie Infectieuse de Langue Française. Antibiothérapie par voie générale en pratique courante dans les infections respiratoires hautes de l'adulte et l'enfant. 2011.

4. Pulcini C, Pauvif L, Paraponaris A, et al. Perceptions and attitudes of French general practitioners towards rapid antigen diagnostic tests in acute pharyngitis using a randomized case vignette study. J Antimicrob Chemother 2012;67:1540-6.

5. Cabana MD, et al. Why don't physicians follow clinical practice guidelines? A framework for improvement. JAMA 1999;282:1458-65.

6. Borg MA. National cultural dimensions as drivers of inappropriate ambulatory care consumption of antibiotics in Europe and their 
relevance to awareness campaigns. J Antimicrob Chemother 2012;67:763-7.

7. Deschepper R, Grigoryan L, Lundborg CS, et al. Are cultural dimensions relevant for explaining cross-national differences in antibiotic use in Europe? BMC Health Serv Res 2008;8:123.

8. Teixeira Rodrigues A, Roque F, Falcao A, et al. Understanding physician antibiotic prescribing behaviour: a systematic review of qualitative studies. Int J Antimicrob Agents 2013;41:203-12.

9. Tonkin-Crine S, Yardley L, Little P. Antibiotic prescribing for acute respiratory tract infections in primary care: a systematic review and meta-ethnography. J Antimicrob Chemother 2011;66:2215-23.
10. Arrondel $\mathrm{L}$, Calvo Pardo $\mathrm{H}$. Les Français sont-ils prudents? Patrimoine et risque sur le marché du travail. Econ Stat 2008;417:27-53.

11. Dohmen T, Falk A, Huffman D, et al. The intergenerational transmission of risk and trust attitudes. Rev Econ Stud 2012;79:645-77.

12. Leydon GM, McDermott L, Moore M, et al. A qualitative study of GP NP and patient views about the use of rapid streptococcal antigen detection tests (RADTs) in primary care: 'swamped with sore throats?'. BMJ Open 2013;3:e002460.

13. Veloski J, et al. Clinical vignette-based surveys: a tool for assessing physician practice variation. Am J Med Qual 2005;20:151-7. 